\title{
Analysis of Airtightness and Air Leakage of Wooden Houses in Korea ${ }^{1}$
}

\author{
Sejong Kim ${ }^{2, \dagger} \cdot$ Yoon-Seong Chang $^{2} \cdot$ Joo-Saeng Park ${ }^{2} \cdot$ Kug-Bo Shim ${ }^{2}$
}

\begin{abstract}
Airtightness of buildings is one of critical aspects of its energy performance. To build up references of airtightness of wooden houses built in Korea, blower door tests have been carried out in 42 houses since 2006. Causes of air leakage were investigated recently. The average value of air change rate was $3.7 \mathrm{~h}^{-1}$ for light frame house and $5.5 \mathrm{~h}^{-1}$ for post-beam construction at ACH50 (air change per hour at $50 \mathrm{~Pa}$ air pressure difference). Foam type insulation was more advantageous in ensuring building airtightness than glass fiber batt. Airtightness of wooden houses which were constructed after 2010 was improved to have less than $1.5 \mathrm{~h}^{-1}$ of ACH50, threshold for application of artificial air change. The average air change rate of CLT (cross laminated timber) houses showed the lowest value, $1.1 \mathrm{~h}^{-1}$, among the tested structures.
\end{abstract}

Keywords : building airtightness, wooden house, air leakage, blower door

\section{INTRODUCTION}

Climate change and high energy cost have increased the demand of energy efficient buildings. Heat loss through building envelope must be reduced to achieve energy efficient building. The heat loss through building envelopes consists of thermal transmittance of building envelope directly, and heat loss due to air leakage through cracks, gaps, or holes of building envelops. That is represented by thermal transmittance and this is done by airtightness of building envelope.

After a couple of oil shocks in 1970s, the amount of thermal insulation in building envelope had increased in order to improve building energy performance through low thermal transmittance of the building envelopes. However, it is difficult to satisfy the needs of residents on low energy consuming house only by improving thermal transmittance of building envelopes. Not only thermal transmittance but also airtightness of building envelope should be improved to achieve expected energy performance because of two major heat loss paths.

Normalized energy demands of a building can be measured by the evaluation of building

1 Date Received September 29, 2017, Date Accepted October 30, 2017

2 Division of Wood Engineering, Department of Forest Products, National Institute of Forest Science, Seoul 02455, Republic of Korea

${ }^{\dagger}$ Corresponding author: Sejong Kim (email : sjno12@gmail.com, ORCID: 0000-0002-0844-7726) 
energy performance based on the thermal transmittance and airtightness of building envelopes. The thermal transmittance is calculated based on the building envelope composition. However, the airtightness of a building should be measured in situ after construction completion, because it is affected by construction accuracy and technical expertise. Consequently, the data bases of building airtightness have been established in northern America (Chan et al., 2013) and Europe (Wei, 2010; Sinnott and Dyer, 2012; Vinha et al., 2015; Bramiana et al., 2016) where studies on low energy houses had implemented in advance. Building airtightness has been measured in Korea (Yoon et al., 2008; Jo, 2010). However, the airtightness measurements did not include wooden house because there were small number of wooden houses constructed annually, less than 2,000 houses permitted up to mid 2000s. Therefore, there is no available airtightness reference value of wooden houses in Korea.

Recently, the Korean government strengthened policy of energy efficiency of existing buildings which were more than $90 \%$ of total buildings. Existing wooden houses in Korea had very poor energy performance because of many defects derived from construction and management without sufficient expertise and regional considerations. So, the current building energy performance of existing wooden houses in Korea were investigated for estimation of energy saving potentials, focusing on the poor building airtightness and its causes.

In this study, evaluation of airtightness and

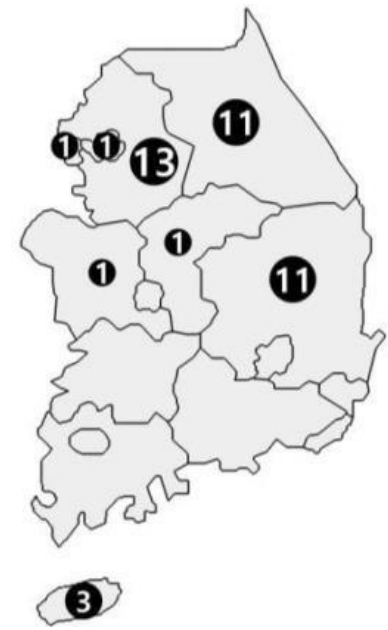

Fig. 1. Location and number of tested wooden houses.

air leakage causes of wooden houses in Korea was implemented for reference value of building energy analysis.

\section{MATERIALS and METHODS}

\subsection{Description of the tested houses}

Blower door test of 42 wooden houses in 16 cities in Korea were carried out since 2006. Ten of them were post and beam construction including Korean traditional wooden house, Han-ok. Two of them were CLT (cross laminated timber) construction. The rest of them were light frame houses.

The number of measurements and the location of tested houses is shown in Fig. 1.

Table 1 shows the specifications of the measured houses. The oldest house was constructed in 2006 and the newest one was done in 2016. Construction types were a) light frame, b) post 
Table 1. Specifications of tested houses

\begin{tabular}{|c|c|c|c|c|c|c|c|}
\hline \multirow{2}{*}{$\begin{array}{c}\text { Construction } \\
\text { year }\end{array}$} & \multirow{2}{*}{ Quantity } & \multicolumn{4}{|c|}{ Construction type } & \multicolumn{2}{|c|}{ Insulation type } \\
\hline & & $\mathrm{LF}^{*}$ & $\mathrm{PnB}^{* *}$ & $\mathrm{CLT}^{* * *}$ & Han-ok & Glass wool & Spray foam \\
\hline 2006 & 1 & & 1 & & & 1 & \\
\hline 2008 & 1 & & 1 & & & 1 & \\
\hline 2010 & 1 & & 1 & & & 1 & \\
\hline \multirow{2}{*}{2011} & 9 & 9 & & & & 9 & \\
\hline & 3 & & 3 & & & 3 & \\
\hline 2012 & 2 & 1 & & & 1 & & 2 \\
\hline \multirow{2}{*}{2013} & 12 & 12 & & & & 12 & \\
\hline & 2 & & 1 & & 1 & & 2 \\
\hline 2014 & 2 & 2 & & & & 2 & \\
\hline \multirow{2}{*}{2015} & 3 & 3 & & & & 3 & \\
\hline & 1 & & 1 & & & & 1 \\
\hline \multirow{2}{*}{2016} & 4 & 3 & & 1 & & 4 & \\
\hline & 1 & & & 1 & & & 1 \\
\hline total & 42 & 30 & 8 & 2 & 2 & 36 & 6 \\
\hline
\end{tabular}

* LF: light frame

** PnB: post and beam

*** CLT: cross laminated timber

and beam, c) CLT and d) Han-ok. Two kinds of insulation type, glass wool and spray foam, were installed. Spray foam type insulation is used for building airtightness in Korea. In some cases, air barrier with thin membrane type was added on building envelops for better building airtightness.

\subsection{Blower Door Test}

In order to determine the air change rate through a building envelope, tracer gas or blower door fan can be used. The blower door test using building pressure differences is more widely used than the other because of convenience of measurement in the field. So, in this study, the blower door test was used for evaluation of building airtightness. The details of test process is described in ASTM E779-87 and ISO 9971. To compare the stability of in-

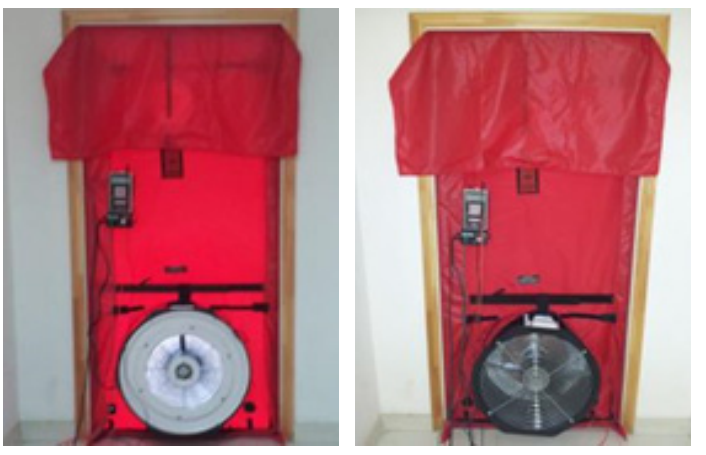

Fig. 2. Depressurization (left) and pressurization (right) mode of blower door test.

sulation, the pressurization and depressurization test mode was applied (Fig. 2).

Actual air change at natural pressure difference is too small and variable to quantify. So, it is obtained by regressive method, which uses measured airflow values at higher building pressure differences and building leakage curve equation follow (1). 

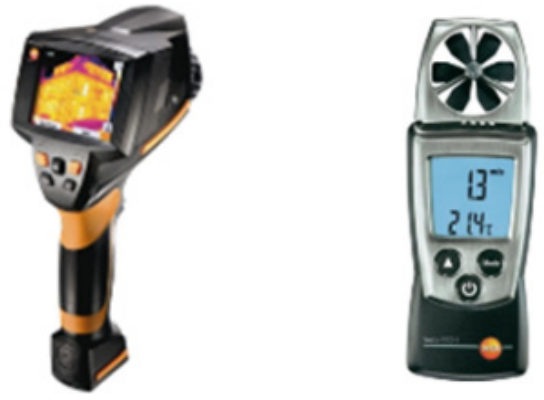

Fig. 3. Infrared camera (left) and vane anemometer (right).

$$
Q=C \times \Delta P^{n}
$$

where: $\mathrm{Q}=$ air flow $\left(\mathrm{m}^{3} / \mathrm{h}\right)$,

$$
\mathrm{C}=\text { flow coefficient }\left(\mathrm{m}^{3} /\left(\mathrm{h} \cdot \mathrm{Pa}^{\mathrm{n}}\right)\right) \text {, }
$$

$\Delta \mathrm{P}=$ pressure difference $(\mathrm{Pa}), \mathrm{n}=$ exponent.

Canadian general standard board (CGSB 149.10-M86), EN13829 and ASTM E779-10, common standards to determine building airtightness, can be distinguished by the range of pressure differences and the number of data points. In this study, CGSB, with 8 data points at relatively lower pressure differences than the others, was used, because all the measured houses were detached ones with smaller air pressure difference than common tall buildings. ACH50, common normalized criteria for building airtightness, is obtained from dividing the air flow at $50 \mathrm{~Pa}$ pressure difference by the inner volume of the building.

\subsection{Inspection of Air Leakage}

In order to find out causes of induced poor building airtightness, infrared camera and vane anemometer were used (Fig. 3). The infrared

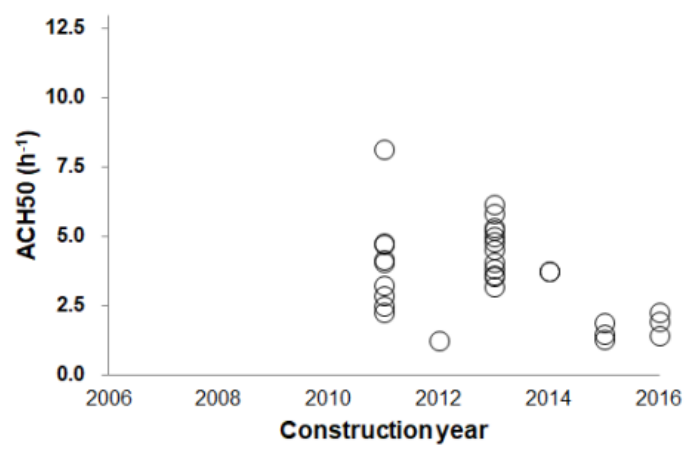

Fig. 4. Building airtightness change of light frame constructions.

camera was used to inspect heat loss spot. The vane anemometer was used to confirm whether the heat loss was induced from air leakage or not.

\section{RESULTS and DISCUSSION}

Bramiana et al. (2016) reviewed some papers concerned with building airtightness and analyse influencing variables for that. In this study, construction year, construction type, insulation type and application of air barrier were use for influencing variables for analysis.

\subsection{Effect of Construction Year on Building Airtightness}

The 30 measurements of building airtightness in light frame houses are shown in Fig. 4. Building airtightness by the construction year had improved gradually. Montoya et al. (2010) and Sinnott et al. (2012) had proved construction year as influencing variable. The air change rate values less than $1.5 \mathrm{~h}^{-1}$ of ACH50 had appeared after 2012. The thermal trans- 


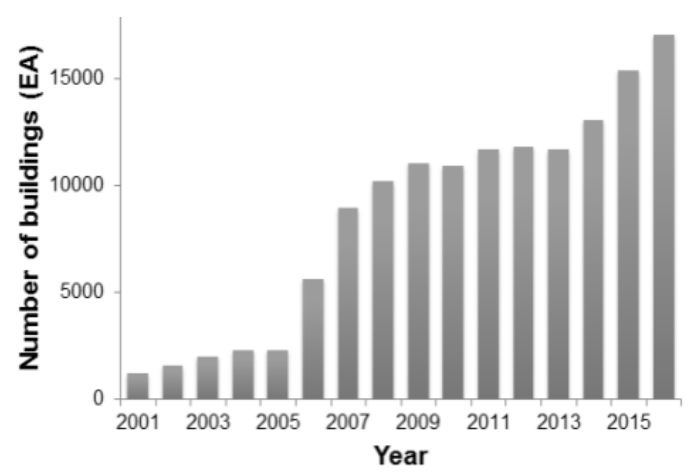

Fig. 5. Number of annual permits of wooden buildings in Korea (Minister of Land, Infrastructure and Transport).

mittance of building envelopes is restricted by the Korean building codes. The Korean government has a plan to strengthen the regulations on thermal transmittance to the goal of zero energy homes by 2025 . For not only this reason but also rapid increase of wooden house demand after 2005 (Fig. 5), the owners and builders of wooden houses had more interest on building energy performance. As a result, the airtightness of Korean wooden houses seems to be improved gradually.

The 8 measurements of building airtightness in post-beam constructions are shown in Fig. 6. As same as light frame, building airtightness had improved gradually except only 1 measurement in 2011. This was obtained from an accommodation in public recreational forest. The highest value of ACH50 in 2011 of light frame house in Figure 4 was also obtained at the same place. Because the accommodation was in public place, it was considered that there was less attention on the air tightness during construction of the house than private house. As a

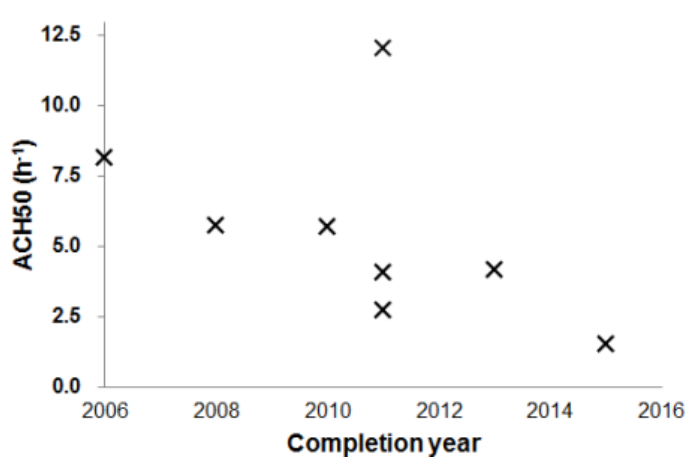

Fig. 6. Building airtightness change of post-beam constructions.

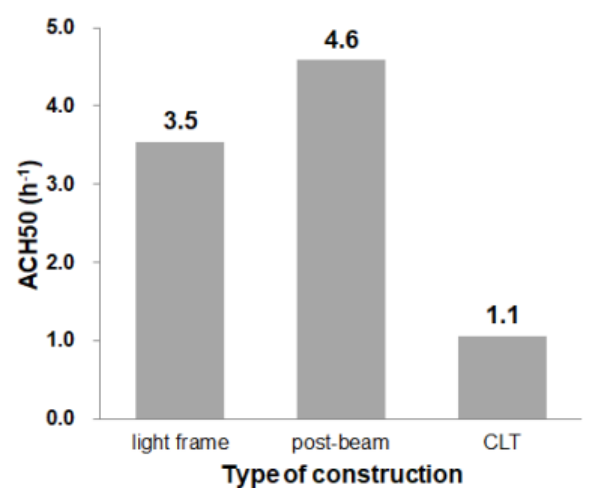

Fig. 7. Building airtightness difference by construction type.

result, poor airtightness was obtained.

Because there were only 2 measurements of CLT and Han-ok constructions, it was difficult to analyse the time effect of building airtightness of them.

\subsection{Effect of Construction Type on Building Airtightness}

Except 2 measurements with poor airtightness from public accommodation, the average values of ACH50 in light frame, post-beam and CLT constructions are compared in Fig. 7. The light 

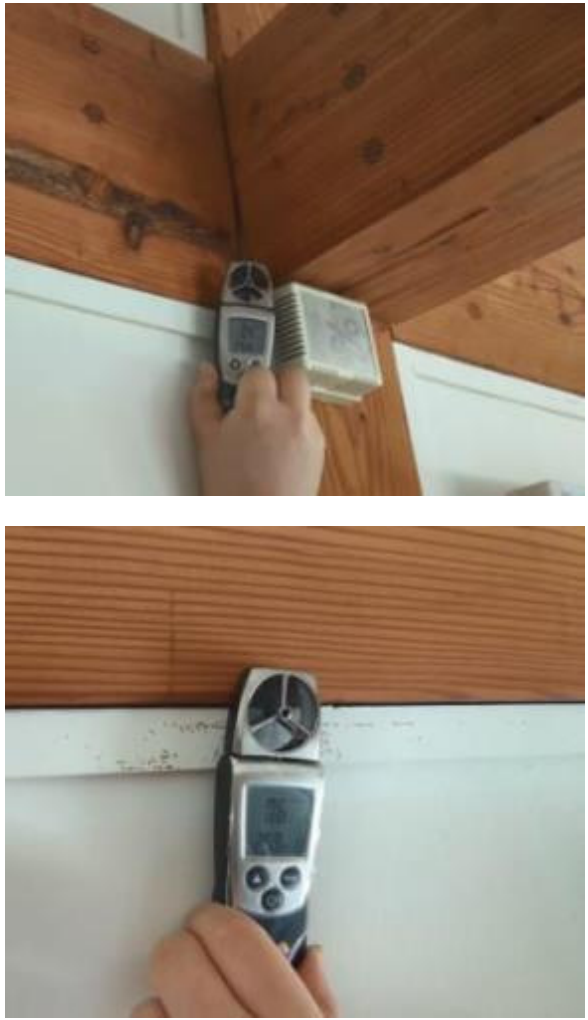

Fig. 8. Air leakage in post-beam construction.

frame houses showed higher airtightness than post-beam construction. Most of post-beam constructions, air leakage was detected at the junctions of walls and post-beam members and the connections of post and beam (Fig. 8).

In the case of CLT houses, ACH50 of them were very low, $1.4 \mathrm{~h}^{-1}$ and $0.7 \mathrm{~h}^{-1}$. The $0.7 \mathrm{~h}^{-1}$ of ACH50 was the smallest value among all of the tested houses. Although building airtightness is affected by various factors, it was clear that CLT construction in Korea was advantageous to keep building airtight.

The measurements of Han-ok were not compared because of deviation in ACH50 values by

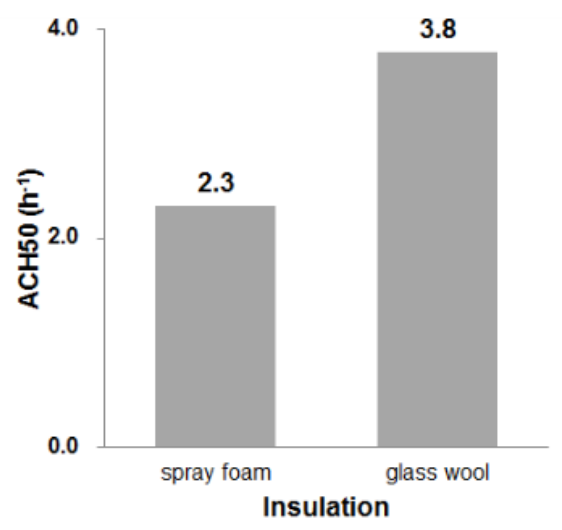

Fig. 9. Comparison of building airtightness of glass wool insulation vs foam type insulation.

$6.9 \mathrm{~h}^{-1}$ and $17.5 \mathrm{~h}^{-1}$. In case of $17.5 \mathrm{~h}^{-1}$, there were many visible gaps between roof and walls. The cause of poor airtightness was very clear. In Korea, Han-ok is managed and constructed not by an architect but by a carpenter.

\subsection{Effects of Insulation Type on Building Airtightness}

Glass wool has been used as common insulation material in most of wooden houses in Korea. The use of spray foam type insulations, such as polyurethane foam, is increasing not only because of installation convenience but because of advantage of airtightness. Among the 42 tested houses, 37 houses used glass wool and the others did polyurethane foam as insulation material. As shown in Fig. 9, spray foam insulation appeared to be more favourable to improve building airtightness than glass wool. Because of unintended gaps while fitting glass wool into wall cavity and deflection of glass wool after fitting, glass wool dose not 


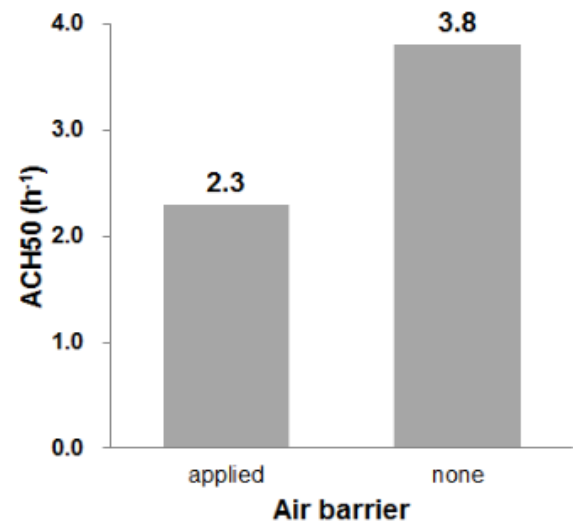

Fig. 10. Effect of air barrier on building airtightness.

have advantage on building airtightness. But, spray foam insulation can do the role of air barrier with flexibility of spraying and rigidity after hardening.

\subsection{Effects of Air Barrier on Building Airtightness}

Recently, the use of air barrier has increased for building airtightness in wooden house in Korea. Use of membrane for building airtightness is well known to be effective (Langmans et al., 2010). 5 houses were installed air barrier at the wall assembly. As shown in Figure 10, the use of air barrier was effective on building airtightness. In case of the 3 houses with air barrier built in 2011, those building airtightness were improved than that of the other 5 houses with no air barrier, even though the houses were constructed at the same site and the same time by the same site manager. With considering time and cost for application of air barrier, unless passive house-level airtight performance

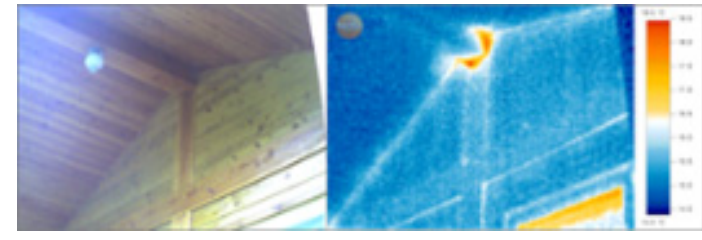

Fig. 11. Infrared image of air leakage of post-beam connection.

(below $0.6 \mathrm{~h}^{-1}$ of $\mathrm{ACH} 50$ ) is required, ensuring construction accuracy is more efficient than install of air barrier. Because, there were 5 measurements of light frame houses with below 1.5 $\mathrm{h}^{-1}$ of ACH50 without air barrier.

\subsection{Defects of Air Leakage}

Fig. 11 shows the infrared image of heat loss induced by air leakage. Post and beam connections were weak area to prevent air leakage. Air leakage of post and beam connections can't be avoid because of dimensional variation of large scale structural members affected by surrounded hygro-thermal conditions.

In many cases, air leakage was detected near the electric components such as lights, electric outlet, light switch and etc. But, there were no air leakage around electrical components when electric distribution was located in the house or when airtightness product was installed for the electrical components.

In case of detached wooden house in suburban region, air leakage was detected near sewer pipe. In that case, the end of sewer pipe was directly exposed to outside. 


\section{CONCLUSIONS}

In this study, evaluation of airtightness and air leakage causes of wooden houses in Korea was implemented for building reference value of building energy analysis.

The conclusions were as follows.

- Building airtightness of wooden house in Korea is gradually improved by the construction year.

- Foam type insulation was more advantageous than glass wool for building airtightness.

- Air barrier was effective to get airtight in wooden house.

- The order of airtight building was CLT, light frame, post-beam, Han-ok.

- Air leakage was mainly at the electrical components, sewer pipe and connections of structural member of post and beam construction.

\section{REFERENCES}

ASTM Standard E779. 1987. Standard test method for determining air leakage rate by fan pressurization.

Bramiana, C.N., Entrop, A.G., Halman, J.I.M. 2016. Relationships between building characteristics and airtightness of Dutch dwellings. Energy Procedia 96: 580 591.

Chan, W.R., Joh, J., Sherman, M.H. 2013. Analysis of air leakage measurements of US houses. Energy and Buildings 66: 616 625.

ISO 9971. 2007. Determination of building airtightness - Fan pressurization method.

Jo, J.H. 2010. Measurements of the Dwelling Unit Airtightness in High-rise Residential Buildings. JOURNAL OF THE ARCHITECTURAL INSTITUTE OF KOREA Planning \& Design 26(10): $337 \sim 344$.

Langmans, J., Klein, R., Paepe, M.D., Roels, S. 2010. Potential of wind barriers to assure airtightness of wood-frame low energy constructions. Energy and Buildings 42(12): 2376 2385.

Montoya M.I, Pastor E., Carrié F.R, Guyot G., Planas E. 2010. Air leakage in catalan dwellings: Developing an airtightness model and leakage airflow prediction. Building and Environment 45: 1458 1469.

Pan, W. 2010. Relationships between air-tightness and its influencing factors of post-2006 new-build dwellings in the UK. Building and Environment 45(11): 2387 2399.

Sinnott, D., Dyer, M. 2012. Air-tightness field data for dwellings in Irelad. Building and Environment 51: 269 275.

Vinha, J., Manelius, E., Korpi, M., Salminen, K., Kurnitski, J., Kiviste, M., Laukkarinen, A. 2015. Airtightness of residential buildings in Finland. Building and Environment 93(2): 128 140.

Yoon, J.H., Park, J.W., Lee, K.S., Baek, N.C., Shin, U.C. 2008. A Study on the Measurement of Airtightness Performance of Detached Houses in Chung-cheong area. Journal of the Korean Solar Energy Society 28(5): 65 71. 